\title{
Autologous CD19-28z Chimeric Antigen Receptor-expressing T-lymphocytes
}

National Cancer Institute

\section{Source}

National Cancer Institute. Autologous CD19-28z Chimeric Antigen Receptor-expressing

T-lymphocytes. NCI Thesaurus. Code C106247.

Genetically modified autologous T-lymphocytes transduced with a replication incompetent retroviral vector expressing a chimeric T cell antigen receptor (CAR) consisting of an anti-CD19 scFv (single chain variable fragment), fused to the extracellular, transmembrane and intracellular signaling domains of the T cell costimulatory receptor CD28 and the cytoplasmic signaling domain of the zeta chain of the TCR/CD3 complex (CD3-zeta) (CAR19-28z), with potential antineoplastic activities. Upon intravenous administration, autologous CD19-28z CAR-expressing T-lymphocytes are directed to CD19-expressing tumor cells, which induces selective toxicity in CD19expressing tumor cells. CD19 antigen is a B-cell specific cell surface antigen expressed in all B-cell lineage malignancies. The CD28 co-stimulatory molecule signaling domain enhances activation and signaling after recognition of CD19. The inclusion of the CD28 signaling domain may increase proliferation of T-cells and antitumor activity compared to the inclusion of the CD3-zeta chain alone. 